\title{
Molecular characterization of enterovirus- A71 in children with acute flaccid paralysis in the Philippines
}

Lea Necitas Apostol ${ }^{1,2^{*}}$ D, Hiroyuki Shimizu ${ }^{3}$, Akira Suzuki ${ }^{1,4}$, Rifaiyah Nur Umami ${ }^{3,5}$, Maria Melissa Ann Jiao ${ }^{2}$, Amado Tandoc $\mathrm{II}^{2}$, Mariko Saito ${ }^{4}$, Socorro Lupisan ${ }^{2}$ and Hitoshi Oshitani ${ }^{1,4}$

\begin{abstract}
Background: Several inactivated enterovirus-A71 (EV-A71) vaccines are currently licensed in China; however, the development of additional EV-A71 vaccines is ongoing, necessitating extensive analysis of the molecular epidemiology of the virus worldwide. Until 2012, laboratory confirmation of EV-A71 for hand, foot, and mouth disease (HFMD) and other associated diseases had not occurred in the Philippines. Because EV-A71 has been linked with cases of acute flaccid paralysis (AFP), AFP surveillance is one strategy for documenting its possible circulation in the country. To expand current knowledge on EV-A71, molecular epidemiologic analysis and genetic characterization of EV-A71 isolates were performed in this study.
\end{abstract}

Methods: A retrospective study was performed to identify and characterize nonpolio enteroviruses (NPEVs) associated with AFP in the Philippines, and nine samples were found to be EV-A71-positive. Following characterization of these EV-A71 isolates, the complete viral protein 1 (VP1) gene was targeted for phylogenetic analysis.

Results: Nine EV-A71 isolates detected in $2000(n=2), 2002(n=4), 2005(n=2)$, and $2010(n=1)$ were characterized using molecular methods. Genomic regions spanning the complete VP1 region were amplified and sequenced using specific primers. Phylogenetic analysis of the full-length VP1 region identified all nine EV-A71 Philippine isolates as belonging to the genogroup C lineage, specifically the C2 cluster. The result indicated a genetic linkage with several strains isolated in Japan and Taiwan, suggesting that strains in the C2 cluster identified in the Asia-Pacific region were circulating in the Philippines.

Conclusion: The study presents the genetic analysis of EV-A71 in the Philippines. Despite some limitations, the study provides additional genetic data on the circulating EV-A71 strains in the Asia-Pacific region, in which information on EV-A71 molecular epidemiology is incomplete. Considering that EV-A71 has a significant public health impact in the region, knowledge of its circulation in each country is important, especially for formulating vaccines covering a wide variety of strains.

Keywords: Acute flaccid paralysis, Enterovirus A71, Genogroup C2, Hand, Foot and Mouth disease, Philippines

\footnotetext{
* Correspondence: leianecitas9780@yahoo.com

${ }^{1}$ Department of Virology, Tohoku University Graduate School of Medicine,

Sendai, Japan

${ }^{2}$ Department of Virology, Research Institute for Tropical Medicine,

Muntinlupa, Philippines

Full list of author information is available at the end of the article
}

(c) The Author(s). 2019 Open Access This article is distributed under the terms of the Creative Commons Attribution 4.0 International License (http://creativecommons.org/licenses/by/4.0/), which permits unrestricted use, distribution, and reproduction in any medium, provided you give appropriate credit to the original author(s) and the source, provide a link to the Creative Commons license, and indicate if changes were made. The Creative Commons Public Domain Dedication waiver (http://creativecommons.org/publicdomain/zero/1.0/) applies to the data made available in this article, unless otherwise stated. 


\section{Background}

Enterovirus-A71 (EV-A71) is an RNA virus belonging to the family Picornaviridae, genus Enterovirus, and species $E V-A$. Using the complete VP1 sequence for genetic classification, EV-A71 is divided into seven genogroups (A-G). Genogroup A contains only one prototype strain $(\mathrm{BrCr})$, and genogroups $\mathrm{B}$ and $\mathrm{C}$ both have five subgenogroups (B1-B5 and $\mathrm{C} 1-\mathrm{C} 5$, respectively). $\mathrm{D}$ belongs to an Indian genogroup, $\mathrm{E}$ and $\mathrm{F}$ are of African origin, and $\mathrm{G}$ was found in India [1-5]. EV-A71 has caused outbreaks of hand, foot, and mouth disease (HFMD) and herpangina, and as a neurotropic virus, it can cause severe neurological complications such as aseptic meningitis, encephalitis, and poliomyelitis-like acute flaccid paralysis (AFP) in infants and young children with significant mortality and morbidity [2, 6-9]. Since its first isolation in 1969 in the USA, large outbreaks have been reported in different parts of the world, and the identification of EV-A71 infection has intensified since 1997, particularly in the Asia-Pacific region including Japan, Malaysia, Brunei, Taiwan, Australia, Singapore, China, and Vietnam [2, 10-12].

Although EV-A71 is implicated in HFMD, which is usually a mild, self-limiting disease, the infection is also associated with severe neurologic diseases including aseptic meningitis, acute encephalitis, polio-like paralysis, acute brainstem encephalitis, cerebellar ataxia, and fulminant neurogenic pulmonary edema [13-15]. Much is known about the epidemiology of EV-A71 infection in many countries in the Asia-Pacific region, but little is known concerning its incidence, genetic diversity, and spectrum of disease in the Philippines. The Philippines is an archipelagic country with three geographical divisions that are further subdivided into 17 administrative regions (Luzon: Regions I, II, III, IV-A, IV-B, and V; Cordillera Administrative Region and National Capital Region [Visayas]: Regions VI, VII, and VIII; and Mindanao: Regions IX, X, XI, XII, XIII, and Autonomous Region for Muslim Mindanao, Fig. 1). Unlike neighboring countries, no specific surveillance for EV-A71 and HFMD was implemented in the Philippines. However, in line with the World Health Organization (WHO) Initiative on Global Poliomyelitis Eradication Program, AFP surveillance was implemented nationwide in 1992 to detect polioviruses and other enteroviruses. Based on the case definition by $\mathrm{WHO}$, which is the detection of AFP in any child younger than 15 years, collection of two stool specimens within 14 days of the date of onset of paralysis is performed [16]. Since the establishment of AFP surveillance in the country, the national reference laboratory has detected large numbers of enteroviruses, including wild-type and vaccine-derived polioviruses, as well as other known enteroviruses. In the Philippines, outbreaks of HFMD and other related infections have been reported only via syndromic approaches, and laboratory identification of the causative agents including EV-A71 was not performed until July 2012. There has been no routine system in the Philippines for detecting circulating
EV-A71 strains excluding those identified via AFP surveillance. Typing of nonpolio enteroviruses (NPEVs) identified during AFP surveillance in the Philippines, including eight EV-A71 strains, has been described [17]. With the significant impact of EV-A71 infection on human health and the need to develop an effective vaccine, defining the genetic characteristics of EV-A71 may expand current knowledge regarding its molecular epidemiology. Thus, this study focused on the detailed genetic characterization of EV-A71 strains associated with AFP to define the molecular characteristics of circulating strains in the Philippines.

\section{Methods}

In total, 18,346 stool samples were collected from children presenting with AFP in the Philippines from 1992 to 2016, and 1332 NPEVs were isolated from these samples. Of these NPEVs, nine EV-A71 isolates were characterized in this study, including eight isolates identified as EV-A71 in a report published in 2012 using partial viral protein 1 (VP1) sequences [17] and an isolate detected in 2010. These isolates were tested using virus isolation and neutralization assays. Virus isolation was performed using a rhabdomyosarcoma cell line, and samples were identified as NPEV via the neutralization test using antisera pools provided by WHO, which contain antibodies against polioviruses and the most commonly observed enteroviruses [16]. All isolates that did not exhibit specific neutralization patterns were regarded as untypable NPEV. Because the antibody for EV-A71 was not included in the antisera pool, EV-A71 was not identified using the neutralization test. The serotypes of untypable NPEVs were further determined using a previously described molecular method for initial confirmation [17]. As the resulting amplicon size in the previous study was approximately $340 \mathrm{bp}$ in size, the determination of genogroup identity may not be reliable. Therefore, amplification of the whole VP1 region, by which enteroviruses are classified, was performed. The complete VP1 genome (891 bp) was amplified using specific EV-A71 PCR primers, and the nucleotide sequence was determined. Nucleic acids were re-extracted from $0.1 \mathrm{ml}$ of each infected tissue culture fluid using a High Pure viral nucleic acid kit (Roche Diagnostics, Mannheim, Germany) according to the manufacturer's instructions. EV-A71-specific RT-PCR was performed using a single-step Access RT-PCR system (Promega, USA). The oligonucleotide primers employed for this assay were as follows: forward primer 71/2349, 5'-GCYTAYATAATAGCAYTGGCGGCAG C-3'; and reverse primer 71/3393, 5'-GGCGGTTRACCA CYCTDAAGTTGCCCAC-3'. The RT-PCR assays were performed using a GeneAmp PCR system 2700 (Applied Biosystems, Foster City, CA, USA) with an uninterrupted thermocycling profile consisting of $45 \mathrm{~min}$ at $48{ }^{\circ} \mathrm{C}$ and 2 min at $94{ }^{\circ} \mathrm{C}$ to inactivate the AMV reverse transcriptase, followed by 35 cycles of $94^{\circ} \mathrm{C}$ for $10 \mathrm{~s}, 50^{\circ} \mathrm{C}$ for $10 \mathrm{~s}$, and 65 ${ }^{\circ} \mathrm{C}$ for $1 \mathrm{~min}$, and a final extension at $65^{\circ} \mathrm{C}$ for $5 \mathrm{~min}$. PCR 


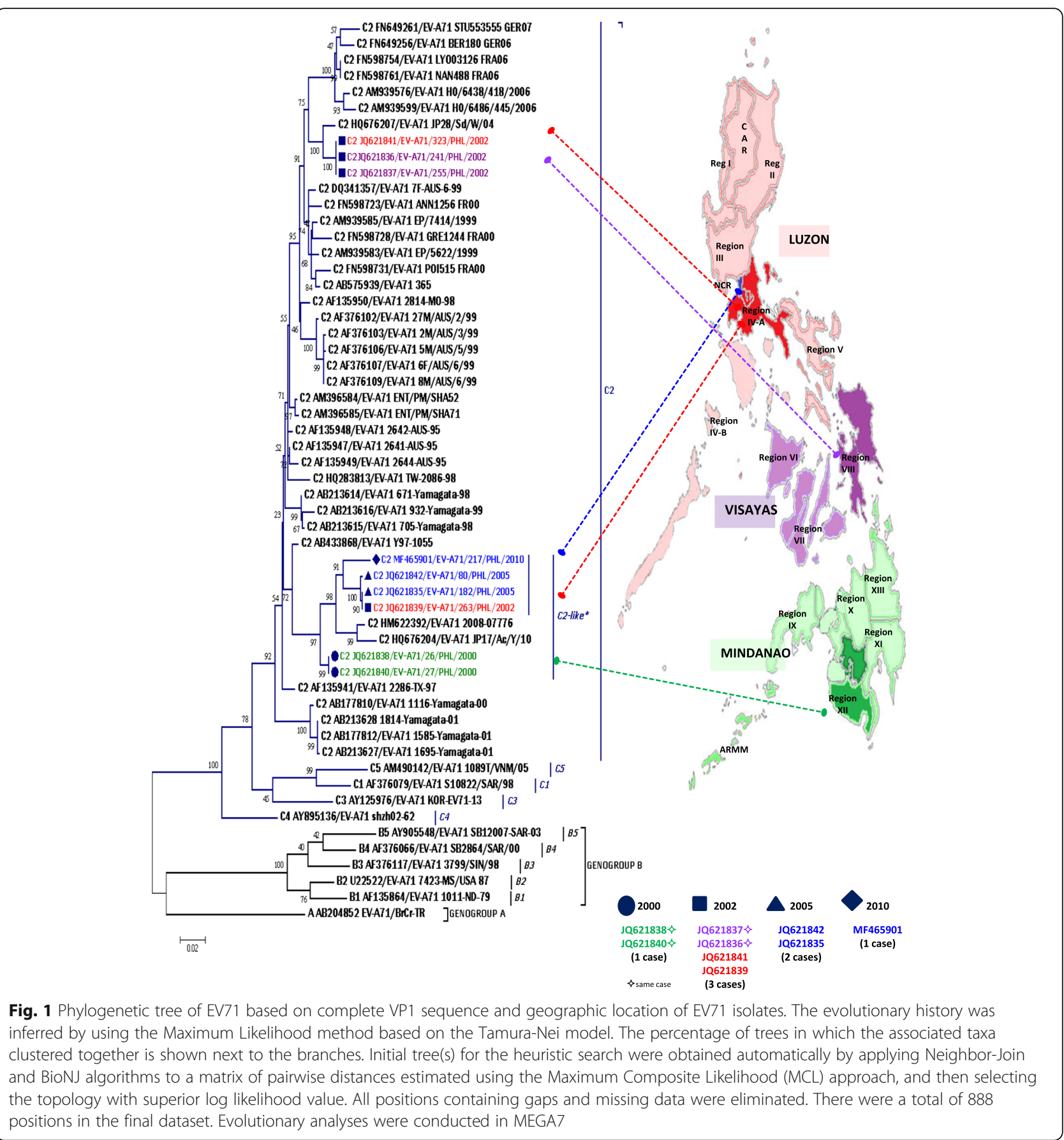

products were visualized in 1\% agarose gel with an expected product size of $1044 \mathrm{bp}$ and purified using the Wizard SV Gel and PCR Clean-up system (Promega, USA) according to the manufacturer's protocol.

The purified PCR products were labeled directly using a cycle sequencing reaction version 3.1 kit and analyzed using a 3100 Avant Genetic Analyzer (Applied Biosystems). Sequencher version 4.10.1 was used to assemble and generate consensus sequences determined from two strands and trimmed to obtain the full-length VP1 sequences using BioEdit v 4.7. MEGA 7.0 was then used to translate nucleotide sequences to amino acid sequences and construct phylogenetic trees using the maximum likelihood method with a bootstrap value of 1000 pseudoreplicates. The substitution model was employed using the Tamura-Nei method. The 
nucleotide sequences were deposited in GenBank under the following accession numbers: JQ621835 (C2/EV-A71/182/PHL/2005), JQ621836 (C2/EVA71/241/PHL/2002), JQ621837 (C2/EV-A71/255/ PHL/2002), JQ621838 (C2/EV-A71/26/PHL/2000), JQ621839 (C2/EV-A71/263/PHL/2002), JQ621840 (C2/EV-A71/27/PHL/2000), JQ621841 (C2/EV-A71/ 323/PHL/2002), JQ621842 (C2/EV-A71/80/PHL/ 2005), and MF465901(C2/EV-A71/217/PHL/2010).

\section{Results}

EV-A71 was detected in 9 of 1332 NPEV-positive stool samples $(0.70 \%)$ collected between 1992 and 2016 from seven children with AFP (Table 1). Of these seven AFP cases, two children had stools positive for EV-A71 in Regions XII (26/ PHL/2000 and 27//PHL/2000) and VIII (241/PHL/2002 and 255/PHL/2002). Phylogenetic analysis of the full-length VP1 region illustrated that all nine Philippine EV-A71 isolates belonged to genogroup $\mathrm{C}$, especially the $\mathrm{C} 2$ and $\mathrm{C} 2$-like clusters (Fig. 1). The Philippine EV-A71 strains (80/PHL/ 2005 [JQ621842]; 182/PHL/2005 [JQ621835]; 263/PHL/2002 [JQ621839]; 217/PHL/2010 [MF465901]; 26/PHL/2000 [JQ621838], and 27/PHL-2000 [JQ621840]) were closely related to a previously reported C2-like subgenogroup [18], especially a Taiwanese isolate obtained in 2008 (GenBank: HM622392) and a Japanese strain detected in 2010 (GenBank: HQ676204) with divergence ranges of $0.028-0.031$ and 0.031-0.037 nucleotides, respectively. Interestingly, the Philippine isolates of the C2-like clade formed two independent subclusters, including one cluster for isolates $80 / \mathrm{PHL} /$ 2005, 182/PHL/2005, 263/PHL/2002, and 217/PHL/2010 and another cluster for $26 / \mathrm{PHL} / 2000$ and $27 / \mathrm{PHL} / 2000$. The other three EV-A71 Philippine isolates (241/PHL/2002, 255/PHL/2002, and 323/PHL/2002) were genetically similar to a Japanese strain isolated in 2004 (GenBank: HQ676207) with 0.013-nucleotide divergence (Table 2). The high homology of these isolates suggests that similar C2 strains are widely circulating in the Asia-Pacific region. Another

Table 1 Distribution of NPEV and EV-A71 isolated and detected per year, Acute Flaccid Paralysis Surveillance, Philippines, 1992-2016

\begin{tabular}{|c|c|c|c|c|}
\hline Year of Isolation & $\begin{array}{l}\text { Number of NPEV } \\
\text { Isolate }\end{array}$ & $\begin{array}{l}\text { Number of EV-A71 } \\
\text { Isolate }\end{array}$ & Number of EV-A71 Case & EV-A71 Positive Rate (\%) \\
\hline 1992 & 16 & 0 & - & - \\
\hline 1993 & 3 & 0 & - & - \\
\hline 1994 & 10 & 0 & - & - \\
\hline 1994 & 11 & 0 & - & - \\
\hline 1996 & 43 & 0 & - & - \\
\hline 1997 & 115 & 0 & - & - \\
\hline 1998 & 64 & 0 & - & - \\
\hline 1999 & 27 & 0 & - & - \\
\hline 2000 & 77 & 2 & 1 & 2.6 \\
\hline 2001 & 69 & 0 & - & - \\
\hline 2002 & 93 & 4 & 3 & 4.3 \\
\hline 2003 & 58 & 0 & - & - \\
\hline 2004 & 26 & 0 & - & - \\
\hline 2005 & 37 & 2 & 2 & 5.4 \\
\hline 2006 & 44 & 0 & - & - \\
\hline 2007 & 51 & 0 & - & - \\
\hline 2008 & 54 & 0 & - & - \\
\hline 2009 & 82 & 0 & - & - \\
\hline 2010 & 50 & 1 & 1 & 2.0 \\
\hline 2011 & 63 & 0 & - & - \\
\hline 2012 & 77 & 0 & - & - \\
\hline 2013 & 72 & 0 & - & - \\
\hline 2014 & 21 & 0 & - & - \\
\hline 2015 & 100 & 0 & - & - \\
\hline 2016 & 69 & 0 & - & - \\
\hline TOTAL & 1332 & 9 & 7 & 0.7 \\
\hline
\end{tabular}


significant finding was the isolation of 323/PHL/2002 in Region IV-A, exhibiting perfect homology with strains isolated in Region VIII from one patient (255/PHL/2002 and 241/ $\mathrm{PHL} / 2002)$ in the same year. A similar finding was also observed for 263/PHL/2002 isolated in 2002, which had high homology with $80 / \mathrm{PHL} / 2005$ and 182/PHL/2005 isolated in 2005 in different geographical areas. All Philippine strains had homologous strains in other Asian countries.

\section{Discussion}

This is the first report of the genetic analysis of EV-A71 strains in the Philippines. The result of previous studies suggested that EV-A71 genogroup B predominates in Southeast Asia and that genogroup $C$ prevails in East Asian countries such as Japan, Taiwan, Korea, and China [2, 19]. EV-A71 outbreaks have been frequently reported in Taiwan, Vietnam, and Malaysia, and considering the geographic location of the Philippines and the highly contagious tendency of EV-A71, it can be assumed that EV-A71 also circulated in the Philippines during the same periods of circulation in neighboring countries.
EV-A71 genogroup $\mathrm{C}$ was detected for the first time in the late 1980s (C1-1986-Australia; C2-1995-Australia; C32000-Korea; C4-1998-Taiwan and; C5-2005-Vietnam) [20], and it has since been circulating in the Western Pacific region, the USA, and European countries such as Norway, France, Germany, Austria, the United Kingdom, and the Netherlands, indicating that genogroup $\mathrm{C}$ circulates globally [21-26]. However, the geographic circulation of subgenogroups within genogroup $\mathrm{C}$ appears to be restricted or limited because subgenogroups C3, C4, and C5 have only been observed in Asian countries. The present report, which used a longitudinal molecular characterization to analyze the entire VP1 region of EV-A71 implicated in AFP in the Philippines, further supports the continuous circulation of genogroup $\mathrm{C}$ in Asian countries including the Philippines.

Based on the available complete VP1 sequences detected between 1970 and 2008, genogroup C is more prevalent than genogroup B; however, the pattern of outbreaks in several Asian countries such as Taiwan indicated the alternating predominance of genogroups $\mathrm{C} 2, \mathrm{~B} 4, \mathrm{C} 4, \mathrm{~B} 5$, and C5 [20]. In the present study, only C2 and C2-like subgenogroups were detected in the Philippines between 2000

Table 2 Estimates of Evolutionary Divergence of subgenogroup C2 with EV-A71 Philippine isolates

\begin{tabular}{|c|c|c|c|c|c|c|c|c|c|c|c|c|}
\hline $\begin{array}{l}\text { Case } \\
\text { (Location) }\end{array}$ & EV-A71 strain & $\begin{array}{l}\text { JQ621838 } \\
\text { JQ621840 }\end{array}$ & $\begin{array}{l}\text { JQ621836 } \\
\text { JQ621837 }\end{array}$ & JQ621841 & JQ621839 & JQ621842 & JQ621835 & MF465901 & $\begin{array}{l}\text { HM } \\
622392\end{array}$ & $\begin{array}{l}\mathrm{HQ} \\
676207\end{array}$ & $\begin{array}{l}\mathrm{HQ} \\
676204\end{array}$ & $\begin{array}{l}A B \\
433868\end{array}$ \\
\hline $\begin{array}{l}1 \text { (Region } \\
\text { XII) }\end{array}$ & $\begin{array}{l}\text { JQ621838 (26/ } \\
\text { PHL/2000) } \\
\text { JQ621840 (27/ } \\
\text { PHL/2000) }\end{array}$ & $x$ & & & & & & & & & & \\
\hline $\begin{array}{l}2 \text { (Region } \\
\text { VIII) }\end{array}$ & $\begin{array}{l}\text { JQ621836 (241/ } \\
\text { PHL/2002) } \\
\text { JQ621837 (255/ } \\
\text { PHL/2002) }\end{array}$ & 0.044 & $x$ & & & & & & & & & \\
\hline $\begin{array}{l}3 \text { (Region } \\
\text { IV-A) }\end{array}$ & $\begin{array}{l}\text { JQ621841 (323/ } \\
\text { PHL/2002) }\end{array}$ & 0.044 & 0 & $x$ & & & & & & & & \\
\hline $\begin{array}{l}4 \text { (Region } \\
\text { IV-A) }\end{array}$ & $\begin{array}{l}\text { JQ621839 (263/ } \\
\text { PHL/2002) }\end{array}$ & 0.026 & 0.054 & 0.054 & $x$ & & & & & & & \\
\hline $\begin{array}{l}5 \text { (Metro } \\
\text { Manila) }\end{array}$ & $\begin{array}{l}\text { JQ621842 (80/ } \\
\text { PHL/2005) }\end{array}$ & 0.026 & 0.054 & 0.054 & 0.001 & $x$ & & & & & & \\
\hline $\begin{array}{l}6 \text { (Metro } \\
\text { Manila) }\end{array}$ & $\begin{array}{l}\text { JQ621835 (182/ } \\
\text { PHL/2005) }\end{array}$ & 0.026 & 0.054 & 0.054 & 0.000 & 0.001 & $x$ & & & & & \\
\hline $\begin{array}{l}7 \text { (Metro } \\
\text { Manila) }\end{array}$ & $\begin{array}{l}\text { MF465901 (S10- } \\
217 / \mathrm{PHL} / 2010)\end{array}$ & 0.030 & 0.059 & 0.024 & 0.024 & 0.024 & 0.024 & $x$ & & & & \\
\hline $\begin{array}{l}\text { Reference } \\
\text { Strain } \\
\text { Taiwan }\end{array}$ & $\begin{array}{l}\text { HM622392 } \\
(2008-07776)\end{array}$ & 0.028 & 0.056 & 0.056 & 0.028 & 0.028 & 0.028 & 0.031 & $x$ & & & \\
\hline $\begin{array}{l}\text { Reference } \\
\text { Strain Japan }\end{array}$ & $\begin{array}{l}\text { HQ676207 } \\
\text { (JP28/Sd/W/04) }\end{array}$ & 0.044 & 0.013 & 0.013 & 0.054 & 0.054 & 0.054 & 0.059 & 0.058 & $x$ & & \\
\hline $\begin{array}{l}\text { Reference } \\
\text { Strain Japan }\end{array}$ & $\begin{array}{l}\text { HQ676204 } \\
(J P 17 / A C / Y / 10)\end{array}$ & 0.032 & 0.056 & 0.056 & 0.031 & 0.031 & 0.031 & 0.037 & 0.013 & 0.060 & $x$ & \\
\hline $\begin{array}{l}\text { Reference } \\
\text { Strain Japan }\end{array}$ & $\begin{array}{l}\text { AB433868 (Y97- } \\
1055)\end{array}$ & 0.022 & 0.032 & 0.032 & 0.038 & 0.038 & 0.038 & 0.042 & 0.040 & 0.032 & 0.043 & $x$ \\
\hline
\end{tabular}

$\mathrm{X}$ indicates value not calculated because the diagonal values would be homologous comparisons. Data represent number of base substitutions per site from between sequences. Standard error estimate(s) are shown above the diagonal and were obtained by a bootstrap procedure (1000 replicates). Analyses were conducted using the Maximum Composite Likelihood model. All positions containing gaps and missing data were eliminated. Evolutionary analyses were conducted in MEGA7 
and 2010. Among the genogroup $\mathrm{C}$ strains detected in the Asia-Pacific region, C2 is apparently not a dominant subgenogroup, as its occurrence is extremely low outside Japan, in which constant and uninterrupted circulation of C2 was observed from 1997 to 2002 [27]. The circulation of $\mathrm{C} 2$ was further observed following HFMD outbreaks in Malaysia, Taiwan, Australia, Thailand, and Singapore between 1997 and 2008 [2, 28-31]. Although global herd immunity against $\mathrm{C} 1$ and $\mathrm{C} 2$ may explain the possible prevalence of epidemics caused by subgenogroups B4 and $\mathrm{C} 4$ in the Asia-Pacific region, previous studies revealed the recurrence of $\mathrm{C} 2$ [21, 23, 32]. The last reported detection of $\mathrm{C} 2$ in the Asia-Pacific region was reported in Japan in 2013. Although $\mathrm{C} 2$ was not detected in the region between 2003 and 2005, the emergence of C2 was documented in Thailand and South Korea in 2006 and 2009, respectively. Likewise, subgenogroup $\mathrm{C} 2$ reappeared in Japan in 2007-2010 [31, 33]. In 2010, a study from Taiwan reported EV-A71 strains (HM622392 and HM622391) belonging to C2-like subgenogroup [18]. The finding of these two C2-like strains collected from different patients in different month in 2008 indicates the circulation of the C2-like viruses at a certain period of time in Taiwan. The phylogenetic analysis in this Taiwan study based on the P1 and $\mathrm{P} 2$ regions of the C2-like strains forming a genetically distinct cluster revealed a possibility of designating a new subgenogroup. Based on the complete VP1 sequence, six Philippine EV-A71 isolates (JQ621835, JQ621838, JQ621839, JQ621840, JQ621842 and MF465901) clearly belonged to the subgenogroup $\mathrm{C} 2$ and further clustered with the reported Taiwan C2-like strains. To know whether the Philippine EV-A71 isolates will form a separate genetic cluster similar to the Taiwan C2-like strains, a full-length genome analysis is needed. Nonetheless, the isolation of C2-like strains in the Philippines prior to its first detection in Taiwan in 2008 gives evidence to the existence of a C2-like subgenogroup and suggests that the Philippine EV-A71 C2-like strains may be the ancestors of the Taiwan C2-like isolates.

During this 25-year period, we found only EV-A71 genogroup C, in particular, subgenogroup C2 in 2002 and subgenogroup C2-like in 2000, 2002, 2005, and 2010 in different geographic locations in the Philippines (Fig. 1). Although the samples characterized in this study were obtained from patients with AFP, the finding of a monophyletic $\mathrm{C} 2$ does not dismiss the fact that it may have been the most prevalent genogroup in 2000-2010, if not the sole subgenogroup present in the country. Whether co-circulation with other EV-A71 genogroups exists in the Philippines remains unknown, and further monitoring of other EV-A71-related diseases, particularly HFMD, is required. Central nervous system involvement as a clinical symptom of AFP is extremely rare. Therefore, the current molecular characterization of nine EV-A71 isolates from patients with AFP may not reveal the entire picture of circulating strains in the country.
Generally, enteroviruses use two evolutionary mechanisms, namely mutation and recombination. Studies have demonstrated the presence of both intra- and intertypic EV-A71 recombinants [34-37]. In both phenomena, altered virologic characteristics have been noted such as changes in antigenicity [18]. Based on two published studies of $\mathrm{C} 2$ recombination events, no $\mathrm{C} 2$ recombinant was found in the Netherlands; however, two strains from Taiwan (HM622391 and HM622392) clustered as C2-like strains exhibited intratypic recombination [18, 38, 39]. When the Philippine EV-A71 isolates were compared with other strains belonging to the same subgenogroup, the most homologous strain related to the six Philippine strains (26/PHL/2000, 27/PHL/2000, 80/PHL/2005, 182/ $\mathrm{PHL} / 2005,263 / \mathrm{PHL} / 2002,217 / \mathrm{PHL} / 2010)$ was the C2-like Taiwanese strain HM622392. HM622392 is a recombinant virus that displayed a significant difference in the neutralization test, having up to a 128 -fold lower neutralization antibody titer than other C2 strains [18]. Whether the Philippine EV-A71 isolates share phenotypic and antigenic characteristics with the known Taiwan strain with a low cross-neutralizing titer against existing $\mathrm{C} 2$ is unknown, and this warrants a full sequence analysis and determination of neutralization antibody titers. Another finding based on the sequence analysis in this study was the identification of EV-A71 strains with perfect homology in the VP1 region isolated in the same year, namely 255/PHL/2002 (JQ621837) and 241/PHL/2002 (JQ621836) from Region VIII, and 323/PHL/2002 (JQ621841) from Region IV-A. Further investigation of these cases revealed no travel history among the patients, suggesting that certain strains were co-circulating in 2002 in the entire country.

Although the present study only examined samples from patients with AFP opposed to a diverse group of individuals presenting with other clinical conditions, this study on EV-A71-associated AFP provides a focal premise that Philippine EV-A71 strains may have neurovirulent potential similarly as strains found in the Asia-Pacific region. Given the partial extent of EV-A71 detection in this study, a significant observation is that subgenogroup C2 might have a role in a broad spectrum of diseases. Many of the subgenogroup $\mathrm{C} 2$ strains detected previously were associated with fatal HFMD, aseptic meningitis, myelitis, encephalitis, bronchiolitis, and herpangina, and samples in this study were comprehensively obtained via 25 years of virologic surveillance of AFP-associated illness.

\section{Conclusions}

This study reports the existence of only EV-A71 C2 subgenogroup in the Philippines, indicating that this subgenogroup is indigenously circulating in the country because it was isolated from different geographic areas. Although large outbreaks of EV-A71 infection have been described in the Asia-Pacific region, no outbreak has occurred in the 
Philippines. The present work could be used for future genetic detection studies on EV-A71 on a much larger scale to determine the overall epidemiology in the country. Given the potential health threat of the virus, EV-A71 should be monitored in the Philippines. Although limited in scope, the present study provides further information on the genetic pool of circulating EV-A71 strains in the Asia-Pacific region.

\section{Abbreviations}

AFP: acute flaccid paralysis; EV-A71: Enterovirus 71; HFMD: hand, foot and mouth disease; NPEV: nonpolio enterovirus; PCR: polymerase chain reaction; VP1: viral protein 1; WHO: World Health Organization

\section{Acknowledgements}

The authors thank the members of the National Polio Laboratory and the Epidemiology Bureau of the Department of Health, Philippines for technical assistance and to WHO-Western Pacific Region for support of the national AFP surveillance program.

\section{Funding}

This work was supported by the Japan Initiative for Global Research Network on Infectious Diseases (J-GRID) and Research Program on Emerging and Reemerging Infectious Diseases from the Japan Agency for Medical Research and Development (AMED) under grant numbers JP17fm0108013 and JP17fk0108204.

\section{Availability of data and materials}

The complete VP1 sequences of the EV-A71 Philippine strains were deposited in GenBank under the following accession numbers: JQ621835, JQ621836, JQ621837, JQ621838, JQ621839, JQ621840, JQ621841, JQ621842, and MF465901.

\section{Authors' contributions}

LNA performed the molecular tests, analyzed data, and drafted the manuscript. RU and MMAJ performed the tests and analyzed the results. MS, AT, and SL contributed to data collection. HS, AS, and $\mathrm{HO}$ analyzed data and drafted the manuscript. All authors read and approved the final manuscript.

\section{Ethics approval and consent to participate}

Not applicable. This research did not involve any human participants and thus, it was exempted from ethics approval.

\section{Consent for publication}

Not applicable.

\section{Competing interests}

The authors declare that they have no competing interests.

\section{Publisher's Note}

Springer Nature remains neutral with regard to jurisdictional claims in published maps and institutional affiliations.

\section{Author details}

${ }^{1}$ Department of Virology, Tohoku University Graduate School of Medicine, Sendai, Japan. ${ }^{2}$ Department of Virology, Research Institute for Tropical Medicine, Muntinlupa, Philippines. ${ }^{3}$ Department of Virology II, National Institute of Infectious Diseases, Musashimurayama, Tokyo, Japan. ${ }^{4}$ TohokuRITM Collaborating Research Center for Emerging and Re-emerging Infectious Diseases, Muntinlupa, Philippines. ${ }^{5}$ Research Center for Biotechnology, Indonesian Institute of Sciences, Cibinong 16911, Indonesia.

\section{Received: 7 May 2018 Accepted: 8 April 2019}

Published online: 02 May 2019

\section{References}

1. Schmidt NJ, Lennette $\mathrm{EH}, \mathrm{Ho} H \mathrm{H}$. An apparently new enterovirus isolated from patients with disease of the central nervous system. J Infect Dis. 1974; 129(3):304-9.
2. Tom S, Penny L, David P, Mary Jane C, Peter M, Mong How O. Virology, epidemiology, pathogenesis, and control of enterovirus 71. Lancet Infect Dis. 2010;10(11):778-90.

3. Bessaud M, Razafindratsimandresy R, Nougairede A, Joffret ML, Deshpande JM, Dubot-Peres A, Heraud JM, de Lamballerie X, Delpeyroux F, Bailly JL. Molecular comparison and evolutionary analyses of VP1 nucleotide sequences of new African human enterovirus 71 isolates reveal a wide genetic diversity. PLoS One. 2014;9(3):e90624.

4. Fernandez-Garcia MD, Kebe O, Fall AD, Dia H, Diop OM, Delpeyroux F, Ndiaye K. Enterovirus A71 Genogroups C and E in children with acute flaccid paralysis, West Africa. Emerg Infect Dis. 2016:22(4):753-5.

5. Saxena VK, Sane S, Nadkarni SS, Sharma DK, Deshpande JM. Genetic diversity of enterovirus A71, India. Emerg Infect Dis. 2015;21(1):123-6.

6. Teoh HL, Mohammad SS, Britton PN, Kandula T, Lorentzos MS, Booy R, Jones CA, Rawlinson W, Ramachandran V, Rodriguez ML, et al. Clinical characteristics and functional motor outcomes of Enterovirus 71 neurological disease in children. JAMA Neurol. 2016;73(3):300-7.

7. Lee KY, Lee YJ, Kim TH, Cheon DS, Nam SO. Clinico-radiological spectrum in enterovirus 71 infection involving the central nervous system in children. J Clin Neurosci. 2014;21(3):416-20.

8. Zhang Q, MacDonald NE, Smith JC, Cai K, Yu H, Li H, Lei C. Severe enterovirus type 71 nervous system infections in children in the Shanghai region of China: clinical manifestations and implications for prevention and care. Pediatr Infect Dis J. 2014;33(5):482-7.

9. Chen KT, Chang HL, Wang ST, Cheng YT, Yang JY. Epidemiologic features of hand-foot-mouth disease and herpangina caused by enterovirus 71 in Taiwan, 1998-2005. Pediatrics. 2007;120(2):e244-52.

10. McMinn P. An overview of the evolution of enterovirus 71 and its clinical and public health significance. FEMS Microbiol Rev. 2002;26(1):91-107.

11. AbuBakar S, Chee H, Al-Kobaisi M, Xiaoshan J, Chua K, Lam S. Identification of enterovirus 71 isolates from an outbreak of hand, foot and mouth disease (HFMD) with fatal cases of encephalomyelitis in Malaysia. Virus Res. 1999;61(1):1-9.

12. AbuBakar S, Sam I, Yusof J, Lim M, Misbah S, MatRahim N, Hooi P. Enterovirus 71 outbreak, Brunei. Emerg Infect Dis. 2009;15(1):79-82.

13. Tu P, Thao N, Perera D, Huu T, Tien N, Thuong T, How O, Cardosa M, McMinn $P$. Epidemiologic and virologic investigation of hand, foot, and mouth disease, southern Vietnam, 2005. Emerg Infect Dis. 2007;13(11):1733-41.

14. McMinn P, Stratov I, Nagarajan L, Davis S. Neurological manifestations of enterovirus 71 infection in children during an outbreak of hand, foot, and mouth disease in Western Australia. Clin Infect Dis. 2001;32(2):236-42.

15. Chen CY, Chang YC, Huang CC, Lui CC, Lee KW, Huang SC. Acute flaccid paralysis in infants and young children with enterovirus 71 infection: MR imaging findings and clinical correlates. AJNR Am J Neuroradiol. 2001;22(1):200-5.

16. Organization WH: polio laboratory manual, 4th edn. Geneva, Switzerland; 2004

17. Apostol LN, Suzuki A, Bautista A, Galang H, Paladin FJ, Fuji N, Lupisan S, Olveda R, Oshitani H. Detection of non-polio enteroviruses from 17 years of virological surveillance of acute flaccid paralysis in the Philippines. J Med Virol. 2012:84(4):624-31.

18. Huang YP, Lin TL, Hsu LC, Chen YJ, Tseng YH, Hsu CC, Fan WB, Yang JY, Chang FY, Wu HS. Genetic diversity and C2-like subgenogroup strains of enterovirus 71, Taiwan, 2008. Virol J. 2010;7:277.

19. Wu WH, Kuo TC, Lin YT, Huang SW, Liu HF, Wang J, Chen YM. Molecular epidemiology of enterovirus 71 infection in the central region of Taiwan from 2002 to 2012. PLoS One. 2013;8(12):e83711.

20. Tee KK, Lam TT, Chan YF, Bible JM, Kamarulzaman A, Tong CY, Takebe Y, Pybus OG. Evolutionary genetics of human enterovirus 71: origin, population dynamics, natural selection, and seasonal periodicity of the VP1 gene. J Virol. 2010;84(7):3339-50.

21. Bible JM, Iturriza-Gomara M, Megson B, Brown D, Pantelidis P, Earl P, Bendig J, Tong CY. Molecular epidemiology of human enterovirus 71 in the United Kingdom from 1998 to 2006. J Clin Microbiol. 2008;46(10):3192-200.

22. McMinn P, Lindsay K, Perera D, Chan H, Chan K, Cardosa M. Phylogenetic analysis of enterovirus 71 strains isolated during linked epidemics in Malaysia, Singapore, and Western Australia. J Virol. 2001;75(16):7732-8.

23. van der Sanden S, Koopmans M, Uslu G, van der Avoort H. Epidemiology of enterovirus 71 in the Netherlands, 1963 to 2008. J Clin Microbiol. 2009;47(9):2826-33.

24. Mirand A, Schuffenecker I, Henquell C, Billaud G, Jugie G, Falcon D, Mahul A Archimbaud C, Terletskaia-Ladwig E, Diedrich S, et al. Phylogenetic evidence for a recent spread of two populations of human enterovirus 71 in European countries. J Gen Virol. 2010;91(Pt 9):2263-77. 
25. Witsø E, Palacios G, Rønningen KS, Cinek O, Janowitz D, Rewers M, Grinde B, Lipkin W. Asymptomatic circulation of HEV71 in Norway. Virus Res. 2007;123(1):19-29.

26. Brown B, Oberste M, Alexander JJ, Kennett M, Pallansch M. Molecular epidemiology and evolution of enterovirus 71 strains isolated from 1970 to 1998. J Virol. 1999;73(12):9969-75.

27. Chang PC, Chen SC, Chen KT. The current status of the disease caused by Enterovirus 71 infections: epidemiology, pathogenesis, molecular epidemiology, and vaccine development. Int J Environ Res Public Health. 2016;13:9.

28. Huang SW, Kiang D, Smith DJ, Wang JR. Evolution of re-emergent virus and its impact on enterovirus 71 epidemics. Exp Biol Med (Maywood). 2011; 236(8):899-908

29. Chong P, Liu CC, Chow YH, Chou AH, Klein M. Review of enterovirus 71 vaccines. Clin Infect Dis. 2015;60(5):797-803.

30. Wu Y, Yeo A, Phoon MC, Tan EL, Poh CL, Quak SH, Chow VT. The largest outbreak of hand; foot and mouth disease in Singapore in 2008: the role of enterovirus 71 and coxsackievirus a strains. Int J Infect Dis. 2010;14(12):e1076-81.

31. Chatproedprai S, Theanboonlers A, Korkong S, Thongmee C, Wananukul S, Poovorawan Y. Clinical and molecular characterization of hand-foot-andmouth disease in Thailand, 2008-2009. Jpn J Infect Dis. 2010;63(4):229-33.

32. van der Sanden S, van der Avoort H, Lemey P, Uslu G, Koopmans M. Evolutionary trajectory of the VP1 gene of human enterovirus 71 genogroup B and C viruses. J Gen Virol. 2010;91(Pt 8):1949-58.

33. Mizuta K, Aoki Y, Matoba Y, Yahagi K, Itagaki T, Katsushima F, Katsushima Y Ito $\mathrm{S}$, Hongo S, Matsuzaki Y. Molecular epidemiology of enterovirus 71 strains isolated from children in Yamagata, Japan, between 1990 and 2013 J Med Microbiol 2014;63(Pt 10):1356-1362

34. Yoke-Fun C, AbuBakar S. Phylogenetic evidence for inter-typic recombination in the emergence of human enterovirus 71 subgenotypes. BMC Microbiol. 2006;6:74.

35. Huang SC, Hsu YW, Wang HC, Huang SW, Kiang D, Tsai HP, Wang SM, Liu CC, Lin KH, Su IJ, et al. Appearance of intratypic recombination of enterovirus 71 in Taiwan from 2002 to 2005. Virus Res. 2008;131(2):250-9.

36. Zhang Y, Zhu Z, Yang W, Ren J, Tan X, Wang Y, Mao N, Xu S, Zhu S, Cui A et al. An emerging recombinant human enterovirus 71 responsible for the 2008 outbreak of hand foot and mouth disease in Fuyang city of China. Virol J. 2010;7:94

37. Yip CC, Lau SK, Zhou B, Zhang MX, Tsoi HW, Chan KH, Chen XC, Woo PC, Yuen KY. Emergence of enterovirus 71 "double-recombinant" strains belonging to a novel genotype D originating from southern China: first evidence for combination of intratypic and intertypic recombination events in EV71. Arch Virol. 2010;155(9):1413-24.

38. van der Sanden S, van Eek J, Martin DP, van der Avoort H, Vennema H, Koopmans M. Detection of recombination breakpoints in the genomes of human enterovirus 71 strains isolated in the Netherlands in epidemic and non-epidemic years, 1963-2010. Infect Genet Evol. 2011;11(5):886-94.

39. Huang $Y P$, Lin $T L, L i n T H, W u ~ H S$. Antigenic and genetic diversity of human enterovirus 71 from 2009 to 2012, Taiwan. PLoS One. 2013;8(11):e80942.

Ready to submit your research? Choose BMC and benefit from:

- fast, convenient online submission

- thorough peer review by experienced researchers in your field

- rapid publication on acceptance

- support for research data, including large and complex data types

- gold Open Access which fosters wider collaboration and increased citations

- maximum visibility for your research: over $100 \mathrm{M}$ website views per year

At $\mathrm{BMC}$, research is always in progress.

Learn more biomedcentral.com/submissions 